\title{
Estudo da prevalência de anticorpos anti-Anaplasma marginale em bovinos de leite da microrregião de Goiânia, pela reação de imunofluorescência indireta e ELISA
}

\section{Studies on the prevalence of antibodies against Anaplasma marginale in dairy cattle in the microregion of Goiânia, by the indirect fluorescent antibody test and ELISA}

\author{
Hélvio Queiróz dos Santos, ${ }^{\star}$ Cláudio Roberto Madruga, ${ }^{\star \star}$ Guido Fontgalland Coelho Linhares ${ }^{\star \star \star}$
}

\begin{abstract}
Resumo
A pesquisa teve como objetivo o cálculo da prevalência de Anaplasma marginale no rebanho bovino de leite da microrregião de Goiânia, por meio da reação de imunofluorescência indireta (RIFI) e reação imunoenzimática indireta (ELISA). No delineamento experimental o mapa da microrregião foi dividido em 47 quadrantes, dos quais 25 foram sorteados para a colheita de material. Em cada propriedade visitada foi colhido sangue aleatoriamente em cerca de $10 \%$ dos animais. Dessa forma, foram colhidas 521 amostras de sangue, número acima do recomendado pelo modelo estatístico adotado.

Do total das amostras testadas, 505 foram positivas à RIFI e 517 ao ELISA, correspondendo a prevalência de $96,92 \%$ e $99,23 \%$, respectivamente. A análise estatística dos resultados obtidos por ambas as técnicas sorológicas revelou uma concordância de $96,16 \%$ entre elas, e nenhuma diferença estatisticamente significativa. Das 25 propriedades rurais visitadas, todas $(100 \%)$ apresentaram rebanhos positivos para os testes sorológicos. Com base nos dados obtidos, a microrregião de Goiânia pôde ser caracterizada como área de estabilidade enzoótica para $A$. marginale, sendo elevado, os riscos de perdas econômicas na introdução de animais suscetíveis provenientes de áreas livres da enfermidade, sem um planejamento profilático adequado.
\end{abstract}

Palavras-chave: Anaplasma marginale; anaplasmose; bovinos; epidemiologia; reação de imunofluorescência indireta; ELISA.

\begin{abstract}
This research was performed to determine Anaplasma marginale prevalence in dairy cattle in the microregion of Goiânia by the indirect fluorescent antibody test (IFAT) and enzime linked immunoassay (ELISA). In the experimental design of this study, the map of the microregion was divided into 47 squares, from which 25 were ramdomly chosen to be visited for blood sampling. Blood was drawn ramdomly from $10 \%$ of the animals in each property. Five hundred and five and 517 out 521 were positive respectively in the IFAT and ELISA, corresponding $92,9 \%$ of prevalence for the former serological test and $99,2 \%$ for the latter. The results did not show any significant statistical difference between both serological test and the agreement was $96,16 \%$. No significant statistical difference was detected between ages. Cattle from all 27 properties were positive for both serological methods. The results of this study caracterized the region as a stable area for $A$. marginale, therefore there is a potential risk of economic losses in the trade of cattle coming in from non enzootic areas.
\end{abstract}

Keywords: Anaplasma marginale; anaplasmosis; cattle; epidemiology; indirect fluorescent antibody test; ELISA.

\section{Introdução}

A anaplasmose é causada pela riquetsia Anaplasma marginale da ordem Riquettsiales, família Anaplasmataceae (Weiss e Moulder, 1984) que ocorre em ruminantes e tem localização intraeritrocítica obrigatória (Ristic, 1981).
A principal forma de transmissão do A. marginale ocorre através de vetores, sendo que várias espécies de carrapatos e insetos hematófagos têm sido apontadas como transmissores em potencial, podendo ainda ser transmitido por via iatrogênica ou intra-uterina (Ribeiro et al., 1985; Guglielmone, 1995).

\footnotetext{
"MédicoVeterinário-Pós-Graduando de Mestrado em Medicina Veterinária/Sanidade Animal da Escola de Veterinária da UFG-Bolsista do CNPq. E-mail: helter@zaz.com.br.

"*Centro Nacional de Pesquisa de Gado de Corte. CNPGG/EMBRAPA. Campo Grandes, MS. E-mail: madruga@ @npgc.embrapa.br.

***Departamento de Medicina Veterinária/Escola de Veterinária/UFG. E-mail: guidofcl@ vet.ufg.br.
} 
A doença apresenta uma ampla distribuição geográfica, ocorrendo nas Américas, na África e na Austrália (Kessler e Schenk, 1998) e, de acordo com Su e Hsu (1993), a enfermidade também é registrada em partes da Europa, na Oceania e no sudoeste da Ásia.

A anaplasmose causa sérios prejuizos econômicos para a bovinocultura em função de danos diretos e indiretos, observados devido à mortalidade, diminuição na produção de carne e leite, custos com medicamentos, premunição ou vacinação (Tapia et al. 1996). Montenegro-James et al. (1991) estimaram prejuizos de aproximadamente 513 milhões de dólares anuais para a América Latina em decorrência desta enfermidade.

No Brasil as estimativas de perdas econômicas devido à tristeza parasitária bovina são escassas. Montenegro-James et al. (1991) fizeram referência a perdas de 90 milhões de dólares anuais para o Rio Grande do Sul. O ministério da Agricultura e Abastecimento (1998) considera que o A. marginale pode ser encontrado em praticamente todo o território nacional, já que seus vetores ocorrem em todo o país, sendo que em 1994 foram registrados 3.906 focos da doença e 8.572 casos.

Estudos sorológicos têm sido realizados em alguns estados da federação. Pelo teste do cartão, Ribeiro e Reis (1981) encontraram soroprevalências para .A. marginale entre $88 \%$ e $92 \%$, em rebanhos de quatro regiões distintas do estado de Minas Gerais. Ribeiro et al. (1984), em levantamento sorológico em bovinos da Zona da Mata Mineira, encontraram $81,1 \%$ dos soros positivos à reação de imunofluorescência indireta (RIFI) e $73,5 \%$ ao teste do cartão na detecção de anticorpos contra - A. marginale. Oliveira et al. (1992) verificaram $16,3 \%$ de prevalência para bezerros em fazendas leiteiras de Sergipe, pelo teste do cartão. Estudando a epidemiologia da anaplasmose no Rio Grande do Sul, Artiles et al. (1995) detectaram prevalência de $64 \%$. Vidotto et al. (1997) relataram resultado de $67,4 \%$ em Londrina, pela RIFI. No ano seguinte, Vidotto et al. (1998), utilizando o teste de ELISA competitivo, reportaram uma prevalência de $87,56 \%$ naquela mesma região. No estado da Bahia, Araújo et al. (1998) apontaram 92,7\% como prevalência de bovinos sororeagentes para $A$. marginale, na microrregião de Jequié e $95,16 \%$ em Vitória da Conquista, pela RIFI.

$\mathrm{Na}$ literatura são inexistentes dados sobre o assunto com referência ao estado de Goiás. O principal objetivo deste trabalho foi realizar o estudo da prevalência de anticorpos antiA. marginale em bovinos de leite, de diferentes faixas etárias, na microrregião de Goiânia, visando obter dados para uma efetiva caracterização epidemiológica da anaplasmose na região.

\section{Material e métodos}

O trabalho foi desenvolvido na microrregião de Goiânia, que ocupa uma área de $6.847,9 \mathrm{~km}^{2}$, situada em região de cerrado do estado de Goiás, com altitude variando de 707 a 1.030 metros e localiza-se entre as latitudes $16^{\circ} 23^{\prime}$ e $16^{\circ} 58^{\prime}$ e as longitudes $48^{\circ} 57^{\prime}$ e $49^{\circ} 31^{\prime}$ (SEPLAN, 1996). O clima da região é tropical com duas estações bem definidas, verão chuvoso, com precipitações máximas de $300 \mathrm{~mm}$, e inverno seco, com mínimas inferiores a $11 \mathrm{~mm}$ (IBGE, 1994). A microrregião possui um rebanho aproximado de 565.710 (SEPLAN, 1996).
O mapa da microrregião de Goiânia lo bi dividido em 47 quadrantes de $225 \mathrm{~km}^{2}$ cada. Posteriormente foi realizado um sorteio de 25 quadrantes, correspondendo a mais de $50 \%$ do total da área abrangida pelo estudo (Alves, 1987). Para cada quadrante sorteado foi escolhida uma propriedade de acordo com a disponibilidade de acesso ao produtor. Foram colhidas amostras de sangue, ao acaso, em bovinos com idade acima de um ano, em aproximadamente $10 \%$ do total de animais de cada propriedade.

O número de amostras para o estudo de prevalência foi calculado de acordo com o Centro Panamericano de Zoonoses (1973), tendo sido encontrado o valor de 180 como o número mínimo de amostras representativo para a população de bovinos dessa microrregião; o trabalho foi realizado utilizandose 521 amostras. $O$ valor utilizado para a prevalência estimada foi de $98 \%$, obtido a partir de um pré-experimento realizado com as 100 amostras de soros colhidos aleatoriamente em bovinos da região. O grau de confiança adotado foi de $95 \%$ e a margem de erro admitida de $5 \%$.

A colheita de sangue foi realizada nos meses de fevereiro e março de 1998, por punção de $10 \mathrm{ml}$ de sangue da veia jugular em tubos de ensaio utilizando-se aguihas $40 \times 16 \mathrm{~mm}$. Após a completa coagulação sangüínea, as amostras foram levadas ao laboratório para centrifugação e separação dos soros, sendo estes distribuídos em alíquotas de $3 \mathrm{ml}$ e congelados a $-70^{\circ} \mathrm{C}$ para posterior utilização nas provas sorológicas.

Os antígenos de $A$. marginale utilizados no teste de ELISA foram produzidos no Centro Nacional de Pesquisa em Gado de Corte (CNPGC), de acordo com Madruga et al. (1996). Para a RIFI os antígenos foram produzidos segundo IICA (1987), a partir de sangue de animais suscetíveis, infectados experimentalmente, durante pique inicial de parasitemia.

Os testes sorológicos foram realizados no laboratório de hemoparasitologia da Embrapa Gado de Corte, conforme técnicas padronizadas por Madruga et al. (1996) para o ELISA e Madruga et al. (1986) para a RIFI.

Resumidamente, o ELISA foi realizado com antígeno bruto obtido a partir de uma parasitemia de $80 \%$ e na concentração de $0,328 \mathrm{mg}$ por poço da placa de 96 poços para ELISA. Os soros controles e teste foram diluídos 1:1000 e o conjugado anti-lg bovino marcado com fosfatase alcalina na diluição 1:12000. A leitura dos resultados foi realizada por espectrofotometria, com filtro de $405 \mathrm{\eta m}$, em um leitor de ELISA. ${ }^{1}$

Para a execução da prova de IFI utilizou-se o conjugado antiIgG bovina com isotiocianato de fluoresceína. ${ }^{2} \mathrm{~A}$ titulação prévia do conjugado foi determinada em 1:640. As amostras de soro foram testadas nas diluições de 1:320 e 1:640 em solução tampão salina fosfatada pH 7,2 (PBS) e a leitura dos resultados foi realizada em microscópio de epifluorescência, ${ }^{3}$ com aumento de $400 x$.

A avaliação da correlação entre os resultados da RIFI e do ELISA foi feita utilizado-se o método do Qui-quadrado segundo Siegel (1979). A concordância entre os dois testes foi defi-

\footnotetext{
1 UV-VIS METROLAB mod-M980 NS - $95129801 \mathrm{~Hz}-50 / 60 \mathrm{~W}-50$.

${ }^{2}$ FITC - Anti-lgG bovina conjugada com isotiocianato de fluoresceina Sigma.

${ }^{3}$ CARL ZEISS - AXIOSKOP HBO 50.
} 
nida conforme Mathias e MacMillan (1995). A correlação entre os resultados da prevalência para as diferentes faixas etárias foi determinada através do teste do Qui-quadrado com correção de Yates. As freqüências relativas e as absolutas referentes às variáveis estudadas foram calculadas e descritas para os testes aplicados (Siegel 1979).

\section{Resultados e discussão}

Entre as 521 amostras de soros testadas, 505 apresentaram resultados positivos ao teste de RIFI, correspondendo a uma prevalência de anticorpos fluorescentes de $96,93 \%$ na população estudada. A prova de ELISA detectou 517 soros positivos, portanto, prevalência de $99,23 \%$ (Tabela 1). Através do tratamento estatístico adotado, as provas de RIFI e ELISA apresentaram diferenças estatisticamente não-significativas e mostraram concordância de $96,16 \%$. Das 25 propriedades rurais visitadas, todas $(100 \%)$ apresentavam rebanho positivo para $A$. marginale por ambos os testes. Das 521 amostras estudadas, 20 (3,83\%) foram negativas à RIFI ou ELISA, sendo que 16 amostras reagiram negativamente à RIFI e somente quatro ao ELISA. Nenhuma amostra foi negativa simultaneamente às duas provas.

Tabela 1: Freqüência relativa e absoluta de bovinos positivos à reação de imunofluorescência indireta (RIFI) e ao ELISA, com relação à idade, na microrregião de Goiânia

\begin{tabular}{|c|c|c|c|c|c|}
\hline \multirow{3}{*}{$\begin{array}{l}\text { Idade } \\
\text { (anos) }\end{array}$} & \multirow[b]{2}{*}{$N^{\circ}$ Amostras } & \multicolumn{2}{|c|}{$\mathrm{RIFI}$} & \multicolumn{2}{|c|}{ ELISA } \\
\hline & & \multirow[t]{2}{*}{ Absoluta } & \multirow[t]{2}{*}{ Relativa (\%) } & \multirow[t]{2}{*}{ Absoluta } & \multirow{2}{*}{$\begin{array}{c}\text { Relativa } \\
(\%)\end{array}$} \\
\hline & & & & & \\
\hline 2 a 3 & 31 & 27 & 87,10 & 31 & 100,00 \\
\hline 3 a 4 & 96 & 93 & 96,87 . & 96 & 100,00 \\
\hline acima de 4 & 394 & 385 & 97,71 & 390 & 98,98 \\
\hline Total & 521 & 505 & 96,93 & 517 & 99,23 \\
\hline
\end{tabular}

Os resultados referentes à prevalência são próximos daqueles verificados por Ribeiro e Reis (1981) e Ribeiro et al. (1984) para diferentes regiões de Minas Gerais, assim como daqueles obtidos por Araújo et al. (1998) na Bahia e por Vidotto et al.

\section{Referências bibliográficas}

ALFARO, C., TOROBENITEZ, M., GARCIA, F., VALLE, A. Epidemiology of bovine anaplasmosis in the State of Monagas, Venezuela. Relationship with extrinsic characteristics of the host. Vet. Trop., v. 23, n. 1, p. 65-79, 1998.

ALVES, L. C. Prevalência da babesiose bovina em gado leiteiro no município de Garanhuns, Estado de Pernambuco. 1987. 123 p. Tese (Mestrado) - Faculdade de Medicina Veterinária e Zootecnia - Universidade de São Paulo.

ARAÚJO, F. R., LEAL, C. R. B., BASTOS, P. A. S., MADRUGA, C. R., MARQUES, A.P. C. Comparação dos testes de imunoadsorção enzimática, conglutinação rápida e imunofluorescência indireta na detecção de anticorpos contra Anaplasma marginale. Rev. Bras. Parasitol. Vet., v. 6, n. 2, supl. 1, 1997.
(1998) em Londrina. Resultados ligeiramente inferiores foram relatados por Vidotto et al. (1997) para a região de Londrina, ao passo que Oliveira et al. (1992) detectaram resultados significativamente inferiores no estado de Sergipe.

Os resultados distintos relativos às taxas de prevalência verificadas entre diferentes regiões, de acordo com Guglielmone (1995) e Kessler e Shenk (1998), podem ser decorrentes das condições climáticas próprias de cada região, que atuam como importante fator de pressão sobre os diferentes níveis de populações de carrapatos e dípteros hematófagos e, dessa forma, determinando características epidemiológicas locais, ou ainda, pela falta de padronização dos testes.

A concordância entre os métodos de RIFI e ELISA, observada neste trabalho, está de acordo com resultados reportados por Nielsen et al. (1996), Araújo et al. (1997), Braz Jr. et al. (1997).

O tratamento estatístico aplicado demonstrou haver diferença estatisticamente não significativa entre os resultados para os diferentes grupos etários. Resultados semelhantes foram relatados por Payne et al. (1988), Tapia et al. (1996) e Alfaro et al. (1998).

Os resultados deste estudo epidemiológico demonstraram uma elevada prevalência de anticorpos anti- $A$. marginale na população de bovinos da microrregião de Goiânia, que, de acordo com conceitos de Mahoney e Ross (1972), adotados por outros autores em estudos epidemiológicos da Tristeza Parasitária Bovina (Wilson e Ronochardjo, 1984; Sanchez et al., 1985; Ortiz, 1985), permitem a caracterização da microrregião como uma área de estabilidade enzoótica para a anaplasmose bovina. As condições climáticas da região, favoráveis à existência dos vetores durante todo o ano, colaboram para esta situação. Portanto, são mínimos os riscos de ocorrência de surtos de anaplasmose com perdas econômicas significativas em bovinos adultos da microrregião de Goiânia. No entanto, a introdução de bovinos nessa região, oriundos de áreas livres ou de áreas de instabilidade enzoótica, constitui-se uma atividade de alto risco, devendo ser precedida de medidas profiláticas específicas.

ARAÚJO, F. R., MADRUGA, C. R., LEAL, C. R. B., BASTOS, P. A. S., MARQUES, A. P. C. Freqüência de anticorpos anti-Anaplasma marginale em rebanhos leiteiros da Bahia. Arq. Bras. Med. Vet. Zoot., v. 50, n. 3, p. 243-246, 1998.

ARTILES, J., ALVES-BRANCO, P. J. F., MARTINS, J. R., CORREA, L. B., SAPPER, M. F. M. Prevalência de Babesia bovis, B. bigemina e Anaplasma marginale no município de Bagé, Rio Grande do Sul. Rev. Bras. Parasitol. Vet., v. 4, n. 2, supl. 1, 1995.

BRAZJr., C. J., PASSOS, L. M. F., LIMA, J. D., RIBEIRO, M. F. B. Comparação entre o ELISA e a reação de imunofluorescência indireta para detecção de anticorpos anti-Anaplasma marginale em bovinos. Arq. Bras. Med. Vet. Zoot., v. 49, n. 5, p. 543-549, 1997.

CENTRO PANAMERICANO DE ZOONOSES. Procedimientos para estudios de prevalencia de enfermedades crónicas en el ganado. Buenos Aires, 1973. 31 p. (Nota Técnica no 18) 
GUGLIELMONE, A. A. Epidemiology of babesiosis and anaplasmosis in South and Central America. Vet. Parasitol., v. 57, p. 109-119, 1995.

IBGE - Instituto Brasileiro de Geografia e Estatística. Zoneamento ecológico e econômico da área do aglomerado de Goiânia. Goiânia, 1994.

IICA - Instituto Interamericano de Cooperación para la Agricultura. Técnicas para el diagnóstico de babesioses y anaplasmosis bovina. San José, Costa Rica, 1987. (Primer informe).

KESSLER, R. H., SCHENK, M. A. M. Carrapato, tristeza parasitária e tripanossomose dos bovinos. Campo Grande: EMBRAPA - CNPGC, 1998. $157 \mathrm{p}$.

MADRUGA, C. R., KESSLER, R. H., SACCO, A. M. S. JESUS, E. F., MIGUITA, C. T. Produção de antígeno e análise preliminar do teste de imunofluorescência indireta para diagnóstico de anticorpos contra Anaplasma marginale. Campo Grande: EMBRAPA - CNPGC. ISSN 0100-7858 (Pesquisa em andamento, $n^{\circ} 31$ ), 1986, 4 p.

MADRUGA, C. R., MARQUES, A. P. C., MIGUITA, M., SCHENK, M.A.M., KESSLER, R. H. A preliminary evaluation of an enzyme linked immunosorbent assay (ELISA) for detection of antibodies against Anaplasma marginale. In: CONGRESSO PANAMERICANODE CIENNCIAS VETERINÁRIAS, 15., 1996, Campo Grande. Anais... Campo Grande: PANVET, 1996. p. 297.

MAHONEY, D. F., ROSS, D. R. Epizootiological factors in the control of bovine babesiosis. Aust. Vet. J., v. 48, p. 292-298, 1972.

MATHIAS, L. A., MacMILLAN, A. P. Comparação de conjugados no teste imunoenzimático competitivo para o diagnóstico sorológico da brucelose bovina. Pes. Vet. Bras., v. 15, n. 4, p.101-105, 1995.

MINISTÉRIODAAGRICULTURA EABASTECIMENTO. Boletim de Defesa Sanitária Animal, v. 27, n. 1-4, 1998.

MONTENEGRO-JAMES, S., GUILLEN, A. T., TORO, M. DOTELISA para el diagnóstico serológico de anaplasmosis y babesiosis bovinas. Rev. Cubana Cien. Vet., v. 23, n. 1, p. 15-24; 1991.

NIELSEN, K., SMITH, P., GALL, D., ESHAIDE, S. T., WAGNER, D., DAJER, A. Development and validation of indirect enzyme immunoassay for detection of antibody to Anaplasma marginale in bovine sera. Vet. Parasitol., v. 67, p. 133-142, 1996.

OLIVEIRA, A. A., PEDREIRA, P. A. S., ALMEIDA, M. F. R. S. Doenças de bezerros II. Epidemiologia da anaplasmose no Estado de Sergipe. Arq. Bras. Med. Vet. Zoot., v. 44, n. 5, p. 377-386, 1992.

ORTIZ, O. B. Consideraciones sobre la epizootiología de anaplasmosis y babesiosis en los bovinos. Rev. ICA, v. 20, 1985.

PAYNE, R. C., WARD, D. E., MURTHALA USMAN, AGUSRUSLI, DEDDY DJAUHARI, AMIR HUSEIN. Prevalence of bovine haemoparasites in Aceh Province of northern Sumatra: implications for imported cattle. Prev. Vet. Med., v. 6, p. 275-283, 1988.
RIBEIRO, M. F. B., LIMA, J. D., GUIMARÃES, A. M., SCATAMBURIO, M. A., MARTINS, N. E. Transmissão congênita da anaplasmose bovina. Arq. Bras. Med. Vet. Zoot., v. 47, n. 3, p. 297-304, 1985.

RIBEIRO, M. F. B., REIS, R. Prevalência da anaplasmose em quatro regiões do estado de Minas Gerais. Arq. Bras. Med. Vet. Zoot., v. 33, n. 1, p. 57-62, 1981.

RIBEIRO, M. F. B., SANTOS, J. L., SALCEDO, J. H. P., FARIA, J. E. Epidemiologia da anaplasmose bovina no Estado de Minas Gerais. Prevalência de anticorpos aglutinantes e fluorescentes na Zona da Mata. Arq. Bras. Med. Vet. Zoot. v. 36, n. 4, p. 425-432, 1984.

RISTIC, M. Anaplasmosis. In: RISTIC, M., McINTYRE. Diseases of cattle in the tropics. The Hague: Martinus Nijhoff Publishers, 1981. p. 327-344.

SANCHEZ, F. L., RUVALCABA, M. F., TORRES, R. A., ALARCON, G.J. C., SANCHEZ, I. E. Prevalencia de anaplasmosis y babesiosis y determinación de la probabilidad diaria de babesiosis en bovinos del municipio de Villa Comaltitlan, Chiapas Tec. Pec. Méxicov. 48 , 1985.

SEPLAN - Secretaria do Planejamento e Desenvolvimento Regional Superintendência de Estatística, Pesquisa e Informação. Anuário Estatístico do Estado de Goiás. 1996.621p.

SIEGEL, S. Estatística não-paramétrica para ciências do comportamento. Recife: MacGraw-Hill do Brasil, 1979, 350 p.

SU, J. F., HSU, F. S. Serological assays and seroprevalence of ruminant Anaplasma marginale infection in Taiwan. J. Cl. Soc. Vet. Sc., v. 19, n. 2, p. 79-89, 1993.

TAPIA, D. G., ROJAS, M. L., BAYÚGAR, R. C., VAZQUEZ, Z. G., ORTIZ, M. A. G., JALIL, P. D., TORRES, R. A. Seroprevalencia de anaplasmosis en explotaciones bovinas de 18 municipios de la zona Norte de Vera Cruz. Tec. Pec. México, v. 34, n. 1, 1996.

VIDOTTO, O., ANDRADE, G. M., AMARAL, C. S. H., BARBOSA, C. S., FREIRE, R. L., ROCHA, M. A.; VIDOTTO, M. C. Freqüência de anticorpos contra Babesia bigemina, B. bovis e Anaplasma marginale em rebanhos leiteiros da região de Londrina, Paraná. Arq. Bras. Vet. Zoot., v. 49, n. 5, p. 655-659, 1997.

VIDOTTO, M. C., VIDOTTO, O., ANDRADE, G. M., PALMER, G. MCELWAIN, T., KNOWLES, D.P. Seroprevalence of Anaplasma marginale in cattle in Parana State, Brazil, by MSP- 5 competitive ELISA. An. New York Acad. Sc., v. 849, p. 424-426, 1998.

WEISS, E., MOULDER, J. W. The rickettsias. In: KRIEG, N. R., HOLT, J. Bergey's Manual of determinative bacteriology. 9. ed. Baltimore: Williams and Wilkins, 1984. p. 687-739.

WILSON, A. J., RONOHARDJO, P. Some factors affecting the control of bovine anaplasmosis with special reference to Australia and Indonesia. Prev. Vet. Med., n. 2, p. 121-134, 1984. 